\title{
Generalized Seizure in Severe Hypertension
}

\section{Mercy Ekeoma Azubuko-Udah, MD¹; Mary Oluwaseun Olowere, MD²; Gabriel Alugba, MD ${ }^{3}$; Elohor Sandra Otite, MD, RN"; Arthur Dilibe, MD5; David Otuada, MD, MPH'; Gibson 0. Anugwom MD, $\mathrm{MSc}^{7}$}

\author{
${ }^{1}$ Triplecord Health, Lugbe, Abuja, Nigeria \\ 20ak Hospital, 191 Lagos Road, Ikorodu, Lagos, Nigeria \\ 3Pentacare Hospital, Moronranti Tolani Street, Kwara, Nigeria \\ ${ }^{4}$ Jersey Shore University Medical Center, Neptune, NJ, USA \\ ${ }^{5}$ Windsor Medical school of Medicine, St Kitts \\ ${ }^{6}$ University of Alabama at Birmingham, Birmingham, AL, USA. \\ ${ }^{7}$ Department of Psychiatry, Houston Behavioral Healthcare Hospital, Houston, TX, USA. \\ *Corresponding author details: Gibson 0. Anugwom; Anugwomgibson1@gmail.com
}

\begin{abstract}
Hypertension can be defined as systolic blood pressure (BP) $\geq 130$ and diastolic blood pressure $\geq 80$, usually associated with multiple adverse clinical outcomes, including stroke, heart failure, myocardial infarction, renal insufficiency/failure, peripheral vascular disease, retinopathy, dementia, and premature mortality. Our patient was a middle-aged man who had an episode of clonic seizure in the background of severe hypertension. EEG revealed bilateral sharp wave activity in the central, parietal, and temporal regions, indicating generalized seizures. There was remission of his seizure after controlling his blood pressure.
\end{abstract}

Keywords: seizure; electroencephalogram; hypertension; blood pressure

\section{INTRODUCTION}

Almost half of all adults who have unprovoked seizures have no known cause, and the rate of unprovoked seizures is much higher in adults than in children. Seizure is defined as a sudden uncontrolled discharge of cerebral neurons due to an imbalance between excitation and inhibition in the brain-this imbalance results in alterations at many levels of brain functioning and neuronal circuits (1). A seizure can be classified into a focal seizure or generalized seizure depending on the brain region it originates. Among various factors which can cause seizures, it is rare for seizures to occur due to hypertension; however, the study by Williams B et al. reported that untreated or poorly controlled hypertension is associated with structural and/or functional changes in the brain, and blood vessels, which can ultimately cause seizures (2). Studies have shown seizures to be associated with hypertension in two ways. First, longstanding hypertension serves as a risk factor for vascular disease, thus predisposing to obvious and subclinical cerebrovascular disease, and as such, posing a risk factor for late-onset seizures (3). This results from adaptive changes occurring in arteries to prevent hyper-perfusion of the brain while maintaining its normal perfusion.

On the other hand, elevated blood pressure above the regulatory threshold can cause vessel injury in the form of fibrinoid necrosis, ischemia, and edema of the brain, which can form a focus for seizure development (4). Hypertension may also be complicated by hypertensive encephalopathy and can present with acute seizures (4). In this case report, we discussed a 43-year-old man with eight years of hypertension but declined any treatment interventions or preventive measures. Consequently, his condition decompensated, and he presented with clonic seizure episodes and severe hypertension.

\section{CASE PRESENTATION}

A 43-year-old male was admitted to the outpatient department due to severe headache and fatigue. He had a temperature of $98 \mathrm{~F}$, blood pressure of $197 / 110$ $\mathrm{mmHg}$, heart rate of 102 beats/minute, and respiratory rate of 22 cycles/minute. He also complained of a severe pounding headache and generalized body weakness. He was diagnosed with hypertension over eight years before the presentation but has not been on antihypertensive medication. He also reported having periods when he goes "blank" and cannot account for the brief period lasting between 5-10 seconds. This has occurred 6-8 times every month for the past four years. He has not been on any medications except occasional aspirin for headaches.

There was no visual deficit, papilledema, abnormal mental status changes, and focal neurological deficits on physical examination. 
On cardiovascular assessment, there was a displacement of the point of the maximum impulse of the heart. The rest of his clinical examination was non-significant. He had an episode of clonic seizure during the examination, which lasted for approximately three minutes, and he was given intravenous diazepam $10 \mathrm{mg}$.
Following the resolution of the seizure episode, he was given $20 \mathrm{mg}$ sublingual nifedipine, and blood pressure of 175/100 mmHg was recorded after 20 minutes. Initial investigations were ordered, and results are reported in tables 1 and 2 and figures 1 and 2.

TABLE 1: Initial Blood work

\begin{tabular}{|c|c|c|}
\hline PARAMETER & LAB VALUE & REFERENCE \\
\hline White blood cell count & $10,200 / \mathrm{mm}^{3}$ & $4,000-11,000$ \\
\hline Red blood cells & 4.4 million cells $/ \mathrm{mm}^{3}$ & $4.35-5.65$ \\
\hline Platelet count & $302,000 / \mathrm{mm}^{3}$ & $150,000-350,000$ \\
\hline Hemoglobin & $13.9 \mathrm{~g} / \mathrm{dL}$ & $14-17$ \\
\hline Hematocrit & $41 \%$ & $40-50$ \\
\hline Serum amylase & $58 \mathrm{IU} / \mathrm{L}$ & $30-110$ \\
\hline Thyroid stimulating hormone & $2.2 \mathrm{mIU} / \mathrm{L}$ & $0.5-5.0$ \\
\hline Serum glucose & $100 \mathrm{mg} / \mathrm{dl}$ & $70-110$ \\
\hline Serum Lipase & $24 \mathrm{IU} / \mathrm{L}$ & $0-160$ \\
\hline Alanine aminotransferase & $24 \mathrm{IU} / \mathrm{L}$ & $7-35$ \\
\hline Aspartate aminotransferase & $27 \mathrm{IU} / \mathrm{L}$ & $8-35$ \\
\hline Total bilirubin & $1.1 \mathrm{mg} / \mathrm{dl}$ & $0.3-1.2$ \\
\hline BUN/creatinine ratio & $22 \mathrm{mg} / \mathrm{dl}$ & $10-20$ \\
\hline Serum creatinine & $1.1 \mathrm{mg} / \mathrm{dl}$ & $0.7-1.2$ \\
\hline Erythrocyte sedimentation rate & 14 & $<22$ \\
\hline Sodium & $143 \mathrm{mmol} / \mathrm{L}$ & $136-145$ \\
\hline Potassium & $4.3 \mathrm{mmol} / \mathrm{L}$ & $3.5-5.0$ \\
\hline Calcium & $7.8 \mathrm{mmol} / \mathrm{L}$ & $9.0-10.5$ \\
\hline Chloride & $101 \mathrm{mg} / \mathrm{dl}$ & $98-106$ \\
\hline Total cholesterol & $5.3 \mathrm{mmol} / \mathrm{L}$ & $0-5.1$ \\
\hline Triglycerides & $0.5 \mathrm{mmol} / \mathrm{L}$ & $0.6-1.9$ \\
\hline High density lipoprotein & $0.7 \mathrm{mmol} / \mathrm{L}$ & $0.9-1.4$ \\
\hline Low density lipoprotein & $4.4 \mathrm{mmol} / \mathrm{L}$ & $0-4.1$ \\
\hline Very low-density lipoprotein & $0.2 \mathrm{mmol} / \mathrm{L}$ & $0-0.9$ \\
\hline
\end{tabular}


TABLE 2: Other Tests

\begin{tabular}{|l|l|}
\hline \multicolumn{1}{|c|}{ OTHER LABS } & RESULT \\
\hline Hepatitis B (HBsAg) & Negative \\
\hline Hepatitis C (HCV) & Negative \\
\hline HIV 1 \& 2 & Negative \\
\hline VDRL & Negative \\
\hline COVID-19 IgG/IgM & Negative \\
\hline
\end{tabular}

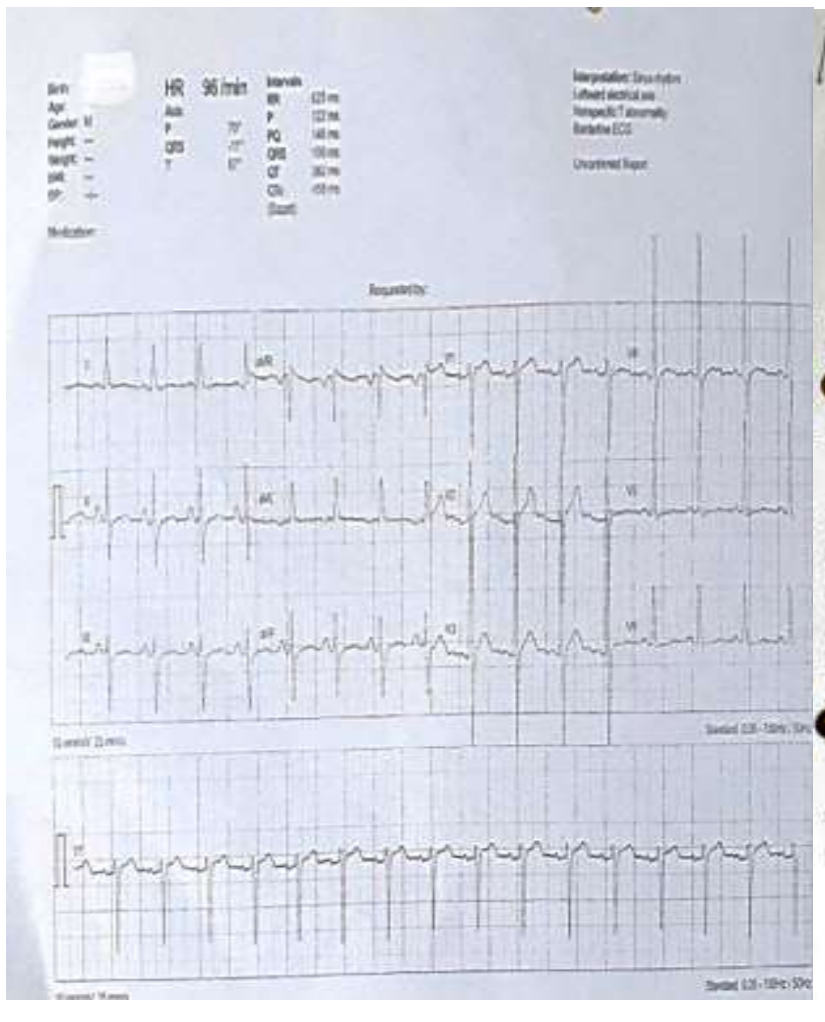

FIGURE 1: Electrocardiograph (Left)

On initial laboratory investigation, BUN/creatinine ratio, total cholesterol, and low-density lipoproteins were elevated, while calcium, triglyceride, and highdensity lipoproteins were below the reference range. Electrocardiography revealed sinus rhythm and left electrical axis deviation, as shown in Figure 1. Awake surface electroencephalography results reported sharp wave activities in the central, parietal, and temporal areas bilaterally, which confirmed a diagnosis of generalized seizures, as shown in Figure 2. He was admitted to the ward, where his blood pressure was controlled with IV Labetalol $20 \mathrm{mg}$. His blood pressure was continuously monitored and was recorded to be 145/86 $\mathrm{mmHg}$ after 48 hours.

A neurologist was consulted, and after a thorough assessment, he was diagnosed with generalized seizure and was prescribed intravenous pre-re Nata (PRN) lorazepam during his stay in the hospital. Over the next week, his blood pressure readings ranged between $115 \mathrm{mmHg}$ and $135 \mathrm{mmHg}$, and there were no episodes of seizures.

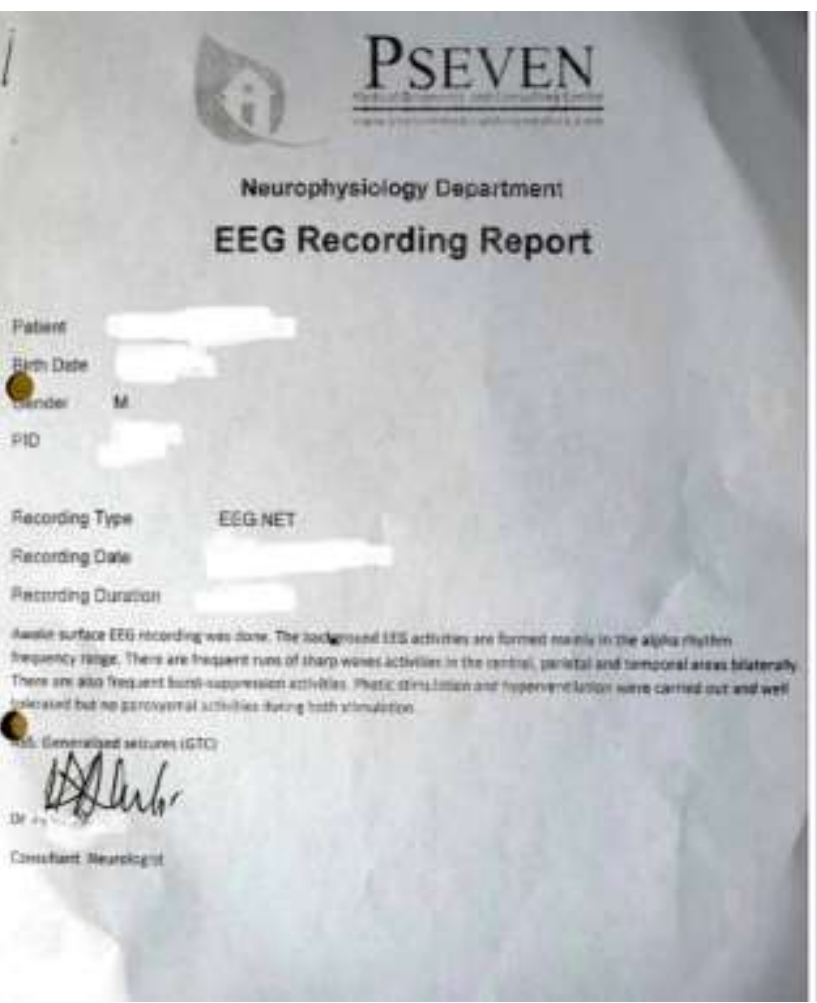

FIGURE 2: Electroencephalograph (Right)

He was counseled to exercise regularly, low sodium diet, have medication compliance, alcohol, and smoking cessation, and have regular blood pressure monitoring. He was discharged on oral Amlodipine $10 \mathrm{mg}$, Carbamazepine $400 \mathrm{mg}$ and Atorvastatin 20 mg. During his follow-up at one month, three months, and six months, home systolic blood pressure readings range between $112 \mathrm{mmHg}$ and $130 \mathrm{mmHg}$. He had carbamazepine for a period of six months, following which he was weaned off. Subsequently, he denied any seizure episodes on his subsequent appointments.

\section{DISCUSSION}

Hypertension can be defined as systolic blood pressure (BP) $\geq 130$ and diastolic blood pressure $\geq 80$ (5). According to the latest American Heart Association guideline (AHA), stage 1 hypertension can be defined as systolic BP between 130-139 or diastolic $\mathrm{BP}$ between 80-89. Stage 2 hypertension is defined as systolic BP at least 140 or diastolic at least 90 (5). 
Based on this definition, our patient has stage 2 hypertension, a severe form of hypertension and is a common cause for hospitalization, accounting for many visits to emergency rooms. It has been linked to multiple adverse clinical outcomes, including stroke, heart failure, myocardial infarction, renal insufficiency/failure, peripheral vascular disease, retinopathy, dementia, and premature mortality (6). Most people do not experience symptoms of high blood pressure until it has progressed to the point of causing significant health concerns. About one-third of individuals with high blood pressure are unaware of their condition and are not receiving treatment to lower their blood pressure (7). When they present, they usually complain of non-specific symptoms such as headache, visual changes, fatigue, dizziness, epistaxis, etc. (8). Our patient was a middle-aged man who had an episode of clonic seizure as a complication of severe hypertension. He was diagnosed with hypertension eight years before the current presentation, but despite the advice of multiple health care providers, he refused further assessment or management of the diagnosis. This is not a common phenomenon, but its association has been shown to be due to cerebral damage resulting from high blood pressure, which could lower the seizure threshold or cause subclinical cerebrovascular disease such as fibrinoid necrosis, ischemia, and edema of the brain, forming a focus for seizure development (9).

Following his presentation, he received diazepam 10 mg to manage his seizure activities and an extensive workup for seizure ordered during his hospitalization. EEG is one of the essential tests since it can reveal the sort of seizure a patient is having. Obtaining continuous EEG monitoring or at least four different EEGs enhances the likelihood of detecting underlying epileptic disease by around 80\%-90\% (10). Our patient's EEG revealed bilateral sharp wave activity in the central, parietal, and temporal regions, indicating generalized seizures. Most times, neuroimaging studies, such as magnetic resonance imaging (MRI) or computer tomography (CT), are also crucial components in working up seizures; however, due to unavailability at the care center, it was deferred.

ECG and blood testing were done as part of the seizure workup to rule out metabolic problems and infectious causes. Despite certain anomalies in his test findings, there was no evidence that any abnormalities caused his seizures in the workup studies (Table 1). The most significant anomaly discovered was a left electrical axis deviation on the ECG with a tall QRS complexes, a frequent finding in longstanding hypertension due to hypertrophy of the left ventricle (11). Other results concerning and warrant continuous surveillance include his elevated BUN/creatinine ratio concerning renal problems. However, these changes in renal values might be an early indicator of renal damage related to his chronically high blood pressure since severe hypertension has been linked to end-organ damage, including kidney impairment (12).
Controlling blood pressure in a hypertensive emergency depends on the doctor's discretion, although most therapies revolve around IV antihypertensives for quick relief (13). Our patient's blood pressure was efficiently managed with $20 \mathrm{mg}$ nifedipine after his initial seizure episode and was switched to IV labetalol during his stay, which significantly lowered his blood pressure value throughout his admission. He was also on PRN lorazepam for any seizure event during his hospital stay but did not have any more seizures. Given the lack of seizure activities and normalized blood pressure, he was discharged on Amlodipine $10 \mathrm{mg}$ for continued management of hypertension, Carbamazepine $400 \mathrm{mg}$ for seizure prophylaxis, and Atorvastatin $20 \mathrm{mg}$ for his abnormal lipid panel. Due to the absence of seizure activity, after a six-month follow-up, he was weaned off carbamazepine and has not had an episode of seizure afterward.

\section{CONCLUSION}

The presentation of generalized seizure in an adult patient on the background of severe hypertension and remission of seizure activities after successfully lowering his blood pressure and stopping carbamazepine in the background of normal blood pressure highlights the importance of constant monitoring and strict adherence control of blood pressure in every adult patient. These measures will likely effectively prevent complications associated with severe hypertension, as seen in our patient.

\section{BIBLIOGRAPHY}

[1] Szczurkowska PJ, Polonis K, Becari C, Hoffmann M, Narkiewicz K, Chrostowska M. Epilepsy and hypertension: The possible link for sudden unexpected death in epilepsy? Cardiol J. 2021;28(2):330-5.

[2] Williams B, Mancia G, Spiering W, Agabiti Rosei E, Azizi M, Burnier M, et al. 2018 ESC/ESH Guidelines for the management of arterial hypertension. Eur Heart J. 2018 Sep 1;39(33):3021-104.

[3] Hiyoshi T, Yagi K. Epilepsy in the elderly. Epilepsia. 2000;41 Suppl 9:31-5.

[4] Sharifian M. Hypertensive encephalopathy. Iran J Child Neurol. 2012;6(3):1-7.

[5] American College of Cardiology. New ACC/AHA High Blood Pressure Guidelines Lower Definition of Hypertension - American College of Cardiology [Internet]. 2017 [cited 2021 Sep 16]. Available from:

https://www.acc.org/latest-incardiology/articles/2017/11/08/11/47/mon5pm-bp-guideline-aha-2017

[6] Flack JM, Peters R, Shafi T, Alrefai H, Nasser SA, Crook E. Prevention of hypertension and its complications: theoretical basis and guidelines for treatment. J Am Soc Nephrol. 2003 Jul;14(7 Suppl 2): S92-8. 
[7] NHLBI. High Blood Pressure | NHLBI, NIH [Internet]. 2020 [cited 2021 Sep 20].

Available from:

https://www.nhlbi.nih.gov/health-

topics/high-blood-pressure

[8] Healthline. High Blood Pressure (Hypertension): Causes, Symptoms, and More [Internet]. 2018 [cited 2021 Sep 20]. Available from: https://www.healthline.com/health/highblood-pressure-hypertension\#symptoms-ofhigh-blood-pressure

[9] Tchekalarova JD, Ivanova N, Atanasova D, Pechlivanova DM, Lazarov N, Kortenska L, et al. Long-Term Treatment with Losartan Attenuates Seizure Activity and Neuronal Damage Without Affecting Behavioral Changes in a Model of Comorbid Hypertension and Epilepsy. Cell Mol Neurobiol. 2016 Aug;36(6):927-41.
[10] King MA, Newton MR, Jackson GD, Fitt GJ, Mitchell LA, Silvapulle MJ, et al. Epileptology of the first-seizure presentation: a clinical, electroencephalographic, and magnetic resonance imaging study of 300 consecutive patients. Lancet. 1998 Sep 26;352(9133):100711.

[11] Bird K, Chan G, Lu H, Greeff H, Allen J, Abbott D, et al. Assessment of Hypertension Using Clinical Electrocardiogram Features: A First-Ever Review. Front Med (Lausanne). 2020 Dec 4; 7:583331.

[12] Schmieder RE. End organ damage in hypertension. Dtsch Arztebl Int. 2010 Dec 10;107(49):866-73.

[13] Aronow WS. Treatment of hypertensive emergencies. Ann Transl Med. 2017 May;5(Suppl 1): S5. 